\title{
Perspective
}

\section{DNA Chips}

\section{The Potential Enhancer of Human Memory}

\author{
Xian Wang, M.D., Ph.D.; Shiqin Xu, M.D., M.P.H.
}

\section{SUMMARY}

Human memory is one of the most important parts that distinguish us from animals. Memory enhancement is a major topic for many researchers of neuroscience and education, but it is not that easy to reach it. Implantation of DNA chips into brain to help memory was seen in science fiction, whereas this kind of hope is also considered by real scientists. By specifically designed DNA chips, can we realize the memory enhancement? It is potentially possible. Based on the memory forming theory and special DNA memorial structure, in combination of electronic circuit, the implantable DNA memory chips would be the promising direction for designing external memory enhancer.m

KEYWORDS Human Memory; DNA Chip; Neuroscience; Education

Sci Insigt. 2018; 2018:e000169. doi:10.15354/si.18.ps027

Copyright (C) 2018 Insights Publisher. This is an open access article distributed under the Creative Commons Attribution License, which permits unrestricted use, distribution, and reproduction in any medium, provided the original work is properly cited. 
$\mathrm{M}$ EMORY is one of the characteristic cornerstones to be human. Recording and storing the surrounding aspects around us for future recall is important to all advanced human function (1).

However, human memory is poorly worked relative to the large quantities of information it's storing. Dr. Gary Marcus, a psychology professor at New York University, says "Human memory is not all that efficiently organized as compared to computer memory. In a computer, every memory goes to a pre-allocated location. In a human being, it's sort of like a shoebox full of memory. It's sort of all there, but it's disorganized. We don't know how to pull out the particular thing that we want" (2). Disorganized human memory is even regarded as the human mind's limitations.

So far, we already have limited solutions to such memory deficiency - memorandum to remind important meetings, new application to learn a foreign language, and plastic device to organize newspapers and books. These things are widely existed to offset the human memory disorganization. Recent years, with the advances of nanotechnology, bioengineering, computers, and neuroscience, it is suggested that we should develop a kind of intellectual chip to implant in our brains that would enable our neurons working like a computer engine and largely improve human memory (3). As early as 20 years ago, British scientists had imagined, "It will be possible to capture data presenting all of a human being's sensory experiences on a single tiny chip implanted in the brain" (4).

Understanding how the brain works and getting into the computer representation is the two hard parts of this technology. In fact, some prototypes of these intellectual chips have already been available. The cochlear chip implant stimulates the auditory nerve and enables totally deaf people to hear sound. With the help of a tiny television camera and ultrasonic distance sensors mounted on eyeglasses and connected to a miniature chip, artificial vision system enables the blind to read letters, watch television, and even walk independently (5).

Other than acting as sensory "amplifiers", implantable brain chip is proposed to function as enhancing memory, enabling invisible communication, and accessing information anywhere or anytime. It's believed that understanding brain code and connecting it with a computer chip is the present frontier to solve human limitations.

However, whether intellectual chips should be widely applied is still controversial. Used for therapy such as remediating mental retardation, facilitating the failing memory or substituting the defective sensory abilities, implantable brain chips is desirable and not controversial when equity and cost are considered.

Other than therapy use, the enhancement function of implantable brain chips such as enhancing human memory may raise a myriad of technical, ethnical, social, and psychological concerns. The first consideration is safety. Evaluation of the costs and benefits of these chips requires weighing of the surgical and long-term risks of implanted materials. Then, due to its widespread societal impact, whether individual request or consent would be sufficient for permitting to implant chips is still under ethnical debate. Thirdly, the usage of chips would change the "norm" of human feeling, supersensory sight, hearing, smell, and touch will sensitize our feeling to the environment. Today's normal might become subnormal, resulting in another area of life.

More importantly, implantable brain chips might change our conception of man and our sense of identity. Imaging that people communicate with chips, the boundaries between self and community, as well as the boundaries between the real and the virtual world will diminish, followed by the change of the sense of self as a unique and isolated individual. Whether such changes would be beneficial to us are unknown.

One frightening outcome of this technology is inequality. It is impossible to ensure a universal coverage of these devices for all people due to resources limitation, which may widen the gap between the haves and the have-nots, further widen the social division between poor and rich persons. Such inequality may even facilitate totalitarian control and monitor of humans, especially used for children, the military, or for criminals. So, taken all of the uncertainties and worries of implantable brain chips, we are convinced that multidisciplinary evaluation is urgently needed from scholars in the fields of computer science, biophysics, law, religion, medicine, philosophy, public policy, and international economy. The development and implementation of implanted brain chips should be, at the very least, regulated at present. 


\section{ARTICLE INFORMATION}

Author Affiliations: Department of Anesthesiology, Hospital of Obstetric and Gynecology, Affiliated to Nanjing Medical University, Nanjing 210004, China (Wang \& Xu).

Author Contributions: Xu had full access to all of the data in the study and takes responsibility for the integrity of the data and the accuracy of the data analysis.

Study concept and design: Wang \& Xu Acquisition, analysis, or interpretation of data: Wang.

Drafting of the manuscript: Wang.
Critical revision of the manuscript for important intellectual content: $\mathrm{Xu}$. Statistical analysis: N/A. Obtained funding: Carson. Administrative, technical, or material support: $\mathrm{Xu}$.

Study supervision: Xu.

Conflict of Interest Disclosures: The author declared no competing interests of this manuscript submitted for publication.

Acknowledgement: None.

Funding/Support: None.

\section{REFERENCES}

1. Implantable brain chips: Ethical and policy issues. 2001 paper by DrEllen McGee and colleague Dr Gerald Q Maguire, Jr.

2. Implant memory chips in our brains. Big Think.
3. The human hard drive: how we make (and lose memories). Big Think/Going Mental.

4. Dawley H. Remember of things past - on a chip. Business week august 5, 1996.
Role of the Funder/Sponsor: N/A.

How to Cite This Paper: Wang X, Xu S. DNA Chips: the Potential Enhancer of Human Memory. Sci Insigt. 2018; 2018:e000169.

Digital Object Identifier (DOI): http://dx.doi.org/10.15354/si.18.ps027.

Article Submission Information: Received, July 20, 2018; Revised: November 1, 2018; Accepted: November 10, 2018.
5. Artificial version system for the blind announced by the Dobelle Institue. Press Release. Science Daily. 